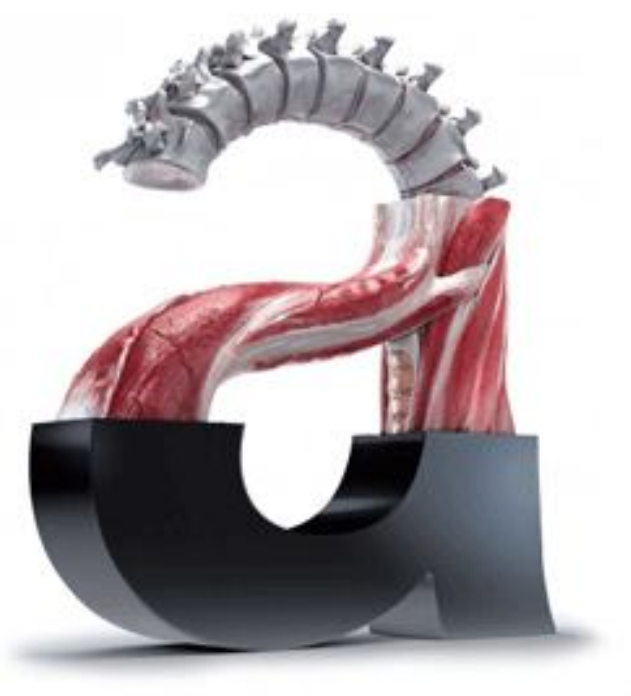

\title{
Linguagem, tecnologia, conhecimento e suas relações no contexto de formação continuada de professores ${ }^{1}$ \\ (Language, Technology, Knowledge and their Relations at Teachers Continuing Education)
}

Fernanda Freire*

\begin{abstract}
Resumo
O artigo apresenta as relações entre linguagem, conhecimento e tecnologia no contexto de formação continuada semipresencial de professores com base em três questões norteadoras - como as novas tecnologias afetam a construção do conhecimento, como o conhecimento constrói novas tecnologias e como as novas tecnologias dão corpo ao conhecimento - discutidas a partir da análise de dados de cursos do Centro de Formação Continuada de Professores do Instituto de Estudos da Linguagem (CEFIEL/Unicamp) que utilizam o ambiente TelEduc.
\end{abstract}

Palavras-chave: linguagem, conhecimento, tecnologia, formação continuada de professores

\begin{abstract}
:
The article presents the relations between language, knowledge and technology in the context of semipresencial teachers continuing education based on three guiding questions - how new technologies affect the construction of knowledge, how knowledge builds new technologies and how new technologies embody the knowledge - discussed as from data courses analysis of the Center for Continuing Education of Teachers of the Institute for the Study of Language (CEFIEL/Unicamp) using the TelEduc environment.
\end{abstract}

Keywords: language, knowledge, technology, teachers continuing education

\footnotetext{
${ }^{1}$ Texto apresentado na mesa-redonda intitulada "Tecnologias de Linguagem e Conhecimento: modos de dizer, de fazer, de divulgar" do Fórum Permanente de Conhecimento \& Tecnologia da Informação: Divulgação Científica e Novas Tecnologias da Linguagem, ocorrido em 14 de maio de 2009. Esta reflexão se insere no âmbito do Projeto de Pós-doutoramento da autora junto ao Instituto de Computação da Universidade Estadual de Campinas (IC - Unicamp) sob supervisão da Profa. Dra. Heloísa Vieira da Rocha.

* Pesquisadora do Núcleo de Informática Aplicada à Educação (NIED/COCEN) credenciada na Pósgraduação do Insituto de Estudos da Linguagem (IEL) desde 2009. Integrante do Conselho de Coordenação do Centro de Formação Continuada de Professores do Instituto de Estudos da Linguagem da Universidade Estadual de Campinas (CEFIEL/Unicamp). Endereço para correspondência: Rua Rua 06 de Agosto, n. 50, Prédio V da Reitoria, 2º piso, Campinas-SP, CEP: 13083-970. Email: ffreire@ unicamp.br
} 


\section{INTRODUÇÃO}

As tecnologias de informação e comunicação têm transformado a vida das pessoas nos centros urbanos: celular, câmera digital, Ipod, vídeo game, tablet e palm. Por meio da digitalização, a computação (a informática e suas aplicações), as comunicações (transmissão e recepção de dados, voz, imagens etc.) e os conteúdos (livros, filmes, pinturas, fotografias, música etc.) convergem: o computador vira um aparelho de TV, a foto sai do álbum para um cd-rom e pelo telefone se conecta na Internet (TAKAHASHI, 2000), uma subversão do conceito de suporte textual (MARCUSCHI, 2003) tal como o conhecemos.

As pessoas participam, direta ou indiretamente, da "digitalização" das práticas sociais: ao consultar um leitor de preços no supermercado, ao pagar uma compra com cartão de crédito, ao enviar um torpedo, ao votar, ao receber uma conta com código de barras. $\mathrm{O}$ denominado letramento digital tem sido considerado uma necessidade e o desconhecimento completo dos usos e das funções do computador é sinônimo de exclusão (BRAGA e RICARTE, 2005).

Novos espaços de leitura e de escrita surgem na Internet - hipertextos, e-mails, blogs, sessões de bate-papos, fóruns de discussão, wikis - dando origem aos chamados "gêneros textuais emergentes" (MARCUSCHI, 2004) ou "gêneros eletrônicos" (PAIVA, 2004).

O objetivo desse artigo é o de discutir as relações entre linguagem e conhecimento a partir do papel da tecnologia na sociedade, em especial, em contextos de formação a distância. Três questões orientam o desenvolvimento do texto: (i) como as novas tecnologias ${ }^{2}$ afetam a construção do conhecimento, (ii) como o conhecimento constrói novas tecnologias e (iii) como as novas tecnologias dão corpo ao conhecimento.

Tais questões são fortemente vinculadas porque entendo que são as práticas sociais $^{3}$ que demandam o desenvolvimento de novas tecnologias (inclusive as da linguagem) gerando novos conhecimentos e novos modos de dizer/de elaborar, criando, por sua vez, novas práticas sociais, numa verdadeira cadeia sem fim, como diria Bakhtin

\footnotetext{
2 Vou me ater às ferramentas de comunicação mediadas por computador síncronas e assíncronas, conhecidas também como CMC, que fazem parte do ambiente de ensino-aprendizagem a distância TelEduc: correio, bate-papo, fóruns, mural etc.

${ }^{3}$ As práticas sociais letradas, segundo Corrêa (2001), podem ser de enunciação oral e de enunciação escrita, havendo circulação entre elas.
} 
(1929/99). As relações, portanto, entre conhecimento, tecnologia e linguagem são datadas historicamente e muito do que se pensa e se diz hoje - tendo as ferramentas de comunicação mediada por computador (ou CMC) como da ordem do "novo" provavelmente já foi dito em relação ao cinema, ao rádio e à TV com base nas práticas sociais de cada época.

Tomo, como ponto de partida para a minha reflexão, o curso do Centro de Formação Continuada de Professores do Instituto de Estudos da Linguagem (CEFIEL) ${ }^{4}$, intitulado "A relação normal/patológico no ensino: cérebro e linguagem". abordamos questões sobre o funcionamento da linguagem e do cérebro e discutimos o modo como ambos atuam na produção/interpretação da escrita. $\mathrm{O}$ curso propõe uma análise crítica do que tradicionalmente se toma como funcionamento cerebral padrão para avaliar o que é patológico, discutindo procedimentos clínicos que excluem tanto o trabalho linguístico-cognitivo do falante/escrevente quanto a diversidade que caracteriza o exercício da linguagem nas várias práticas sociais dentro e fora da escola.

Esse curso - e mais outros 14, em diferentes áreas temáticas - se pauta em uma metodologia especialmente elaborada para cursos semipresenciais (mais a distância do que presencial; das $100 \mathrm{~h}$ apenas 24 são presenciais) continuamente renovada pelas avaliações particular (de cada curso) e geral (de todos os cursos) a cada oferecimento ${ }^{6}$. Trata-se de uma metodologia fortemente focada na interação e, portanto, no uso das ferramentas de comunicação do TelEduc ${ }^{7}$, ambiente de ensino-aprendizagem desenvolvido pelo Núcleo de Informática Aplicada à Educação (NIED) em parceria com o Instituto de Computação (IC), ambos da Unicamp, e adotado pelo CEFIEL.

Os cursos do CEFIEL têm em comum uma certa concepção de formação de professores que se afasta de uma formação compensatória para se propor como espaço de reflexão prático-teórica. A inversão da expressão é proposital: partimos de atividades práticas para dar vida aos conceitos desenvolvidos ao longo dos cursos. O professor em formação, ao fazer a atividade, articula vários saberes - o que já conhece do assunto, como trabalha com aquele tópico em sala de aula, suas crenças, seus valores, sua história pessoal e profissional - e o que está aprendendo durante o curso, seja por meio

\footnotetext{
${ }^{4}$ http://www.iel.unicamp.br/cefiel/

5 Esse curso é coordenado pela Profa. Maria Irma Hadler Coudry e por mim.

6 Desde 2005 temos oferecido esses cursos para professores de escolas públicas de secretarias de educação de IDEB (Índices de Desenvolvimento da Educação Básica) baixo, uma iniciativa da Rede Nacional de Formação Continuada do Ministério da Educação (http://portal.mec.gov.br/ ).

${ }^{7}$ http://www.teleduc.org.br/
} 
das leituras sugeridas, das discussões coletivas, da leitura dos trabalhos dos colegas, dos comentários que seus trabalhos recebem de todos.

Essas diferentes vivências demandam diferentes papéis discursivos - leitor de si mesmo, leitor do outro, escrevente, comentador, debatedor etc. -, o que ajuda o professor em formação a conceber a leitura e a escrita para além de uma visão normativa e ortográfica de língua, um dos objetivos comuns aos cursos do CEFIEL (Freire et al., 2007).

Os professores de escola pública não são, em sua maioria, o que se pode chamar de internautas. Ao contrário, muitos deles podem ser ainda considerados tímidos usuários de tecnologias de informação e comunicação. No entanto, como todos nós, também esse grupo (ou comunidade discursiva, tal como define Maingueneau, 1998; Charadeau \& Maingueneau, $2006^{8}$ ) é heterogêneo, inclusive em relação ao modo como seus integrantes usam essas tecnologias.

É a partir do uso que esse grupo particular faz da tecnologia - no contexto de formação continuada - que passo, então, a discutir as relações entre linguagem, tecnologia e conhecimento.

\section{COMO AS NOVAS TECNOLOGIAS AFETAM A CONSTRUÇÃO DO CONHECIMENTO?}

Para ilustrar o modo como isso ocorre neste contexto particular escolho a ferramenta Portfólio do ambiente TelEduc.

\footnotetext{
${ }^{8}$ Para Charadeau e Maingueneau o conceito de comunidade discursiva é solidário ao de formação discursiva. A hipótese é que não basta opor as formações discursivas em termos puramente textuais porque de um discurso a outro há mudanças na estrutura e no funcionamento dos grupos que produzem esses discursos. Os modos de organização dos homens e de seus discursos são, pois, indissociáveis; as doutrinas são inseparáveis das instituições que as fazem emergir e que as mantêm (Charadeau \& Maingueneau, 2006: 108).
} 


\begin{tabular}{|c|c|c|c|c|}
\hline $\begin{array}{l}\text { Portfólio - Portfó } \\
\underbrace{}_{\text {Raiz }} \quad \text { Dos Santos }\end{array}$ & idual & & & Busca Aiuda \\
\hline Meus Portfólios & Portfólios Individuais & Portfólios de Grupos & Portfóliose & errados \\
\hline & & & & \\
\hline Itens & Data & Compartilhamento & Comentários & Avaliaçäo \\
\hline 娄 Atividade_Agenda0 & $05 / 03 / 2008$ & $\begin{array}{l}\text { Compartilhado com } \\
\text { Formadores }\end{array}$ & & Não \\
\hline 圈 Ativ_Agenda2 & $17 / 03 / 2008$ & Totalmente Compartilhado & & Não \\
\hline 圈 Trabalho & $27 / 03 / 2008$ & Totalmente Compartilhado & $\checkmark$ & Năo \\
\hline 园 Agenda 4 & $29 / 03 / 2008$ & Totalmente Compartilhado & $d \gamma$ & Nẫo \\
\hline 国 Agenda 6 & $12 / 04 / 2008$ & Totalmente Compartilhadd & $d v$ & Nẵo \\
\hline
\end{tabular}

Figura 1: Visão geral da ferramenta Portfólio (TelEduc versão 3.3.8)

Figura 1: http://teleduc.nied.unicamp.br/-teleduc/

Nesta ferramenta os participantes do curso podem armazenar textos e arquivos utilizados e/ou desenvolvidos durante o curso, bem como endereços da Internet. Esses dados podem ser particulares, compartilhados apenas com os formadores ou compartilhados com todos os participantes do curso. Podem ainda ser compartilhados com integrantes de um mesmo grupo, no caso do Portfólio de Grupo. Quando compartilhado, os participantes podem ver os demais Portfólios e comentá-los. Duas características do Portfólio são, pois, importantes para a construção do conhecimento: o modo de compartilhamento e a possibilidade de postar comentários.

Os comentários podem ter diferentes propósitos. Assim, uma mesma ferramenta - neste caso, o Portfólio - a depender da forma como é usada nesse contexto de formação, serve a diferentes conhecimentos como mostra o a Figura 2: 


\begin{tabular}{|c|c|c|c|}
\hline \multicolumn{4}{|c|}{ Portfólio } \\
\hline Conhecimento-alvo & Metodologia & Compartilhamento & Comentários \\
\hline Produção de texto & $\begin{array}{l}\text { 1. Escrita e reescrita } \\
\text { Iongitudinal } \\
\text { Memorial História da } \\
\text { Escrita }\end{array}$ & Total & $\begin{array}{l}\text { Todos os participantes } \\
\text { "críticos" }\end{array}$ \\
\hline $\begin{array}{l}\text { Refinamento de } \\
\text { conceitos }\end{array}$ & $\begin{array}{l}\text { 2. Escrita e reescrita } \\
\text { duas versões } \\
\text { Chico Bento }\end{array}$ & Total & $\begin{array}{l}\text { Formadores (não } \\
\text { exclusivamente) } \\
\text { "diálogo teórico" }\end{array}$ \\
\hline $\begin{array}{l}\text { Confronto de pontos } \\
\text { de vista }\end{array}$ & $\begin{array}{l}\text { 3. Escrita e reescrita } \\
\text { Chico Bento }\end{array}$ & Total & $\begin{array}{l}\text { Todos os participantes } \\
\text { "trabalho colaborativo" }\end{array}$ \\
\hline
\end{tabular}

Figura 2: modos de uso do Portfólio

No primeiro caso - produção textual - propomos ao professor em formação que escreva um memorial sobre a sua História de Escrita, ocasião em que cada um recorda a sua história por meio da escrita e da reescrita ao longo do curso. A cada semana o professor em formação compartilha com os demais participantes uma nova versão do memorial (Figura 3).

\begin{tabular}{|c|c|c|c|}
\hline \multicolumn{3}{|c|}{ Portfollios Individuais } & \multirow{2}{*}{ Portfólios } \\
\hline \multicolumn{3}{|c|}{ 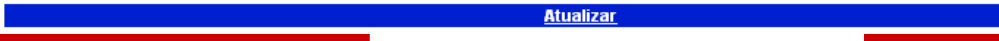 } & \\
\hline Itens & Data & Compartilhamento & Comentários \\
\hline$\square$ memorialparte I (1 item) & $13 / 09 / 2006$ & & $\checkmark r v$ \\
\hline 圈 Atividade da agenda 0 & $13 / 09 / 2006$ & Totalmente Compartilhado & $\checkmark r$ \\
\hline 眯 Questionário Cefiel & $13 / 09 / 2006$ & Totalmente Compartilhado & \\
\hline 粵 Memorial_versẫo_1 & $21 / 09 / 2006$ & Totalmente Compartilhado & $4 d r$ \\
\hline 圈 Atividade da agenda 2 - Chico Bento & $22 / 09 / 2006$ & Totalmente Compartilhado & $\checkmark r$ \\
\hline 粵 Memorial_versẫo_2 & $01 / 10 / 2006$ & Totalmente Compartilhado & $4 \sqrt{2}$ \\
\hline 圈 Memorial_versẫo_3 & $07 / 10 / 2006$ & Totalmente Compartilhado & $\checkmark r$ \\
\hline 国 Atividade_agenda_4 & $07 / 10 / 2006$ & Totalmente Compartilhado & $\checkmark r$ \\
\hline 国 Memorial versẫo_4 & $15 / 10 / 2006$ & Totalmente Compartilhado & $\checkmark r$ \\
\hline 国 Memorial versẩo 5 & $21 / 10 / 2006$ & Totalmente Compartilhado & $\checkmark r$ \\
\hline 国 Atividade_agenda_E & $21 / 10 / 2006$ & Totalmente Compartilhado & $\checkmark \sqrt{ }$ \\
\hline 圈 Atividade_agenda_7 & $28 / 10 / 2006$ & Totalmente Compartilhado & $\checkmark$ \\
\hline
\end{tabular}

Figura 3: Diferentes versões do memorial e os comentários recebidos pelo autor http://www.cefiel.iel.unicamp.br/ teleduc3/cursos/aplic/index.php?cod_curso $=340^{9}$

Embora o objetivo dessa atividade seja o de propor um exercício continuado com e sobre a escrita, ela também permite problematizar outras questões de interesse para o curso: a complexidade da aquisição da leitura e da escrita; as condições

\footnotetext{
${ }^{9}$ Exemplo retirado do Curso a relação normal/patológico no ensino: cérebro e linguagem oferecido no período de 04/09/2006 a 06/11/2006, coordenado pela Profa. Maria Irma Hadler Coudry e por mim.
} 
sóciohistóricas e psíquicas que afetam esse aprendizado; as instabilidades próprias desse processo, levando o professor em formação a reinterpretar a relação de seus alunos com a leitura e com a escrita, bem como a rever o modo como eles lêem (e interferem) os escritos de seus alunos.

Todos são convidados a ler os memoriais livremente e postar algum comentário. E que comentários são esses? Em geral os leitores dizem o que acharam da história, apontam relações que fazem com as suas histórias pessoais, falam a respeito do modo como o texto está escrito, o que pode ser tratado de outra forma etc. Comportam-se como uma espécie de "críticos" e os autores, às vezes, respondem aos comentários recebidos e/ou incorporam as sugestões que lhes foram feitas.

Cria-se, então, uma rede de escreventes e leitores.

O segundo modo de usar o Portfólio visa o refinamento de conceitos tratados ao longo do curso. Cada curso se apóia em um texto - os fascículos da Coleção Linguagem e Letramento em foco - que apresenta e discute - por meio de dados aspectos teórico-práticos que importam à temática do curso.

Com o objetivo de relacionar a teoria com a vivência educacional do professor em formação preparamos um conjunto de perguntas a partir de uma situação-problema que pode ser de diferentes tipos. Apresento, como exemplo, uma atividade baseada em um episódio do Chico Bento, conhecido personagem caipira de Maurício de Sousa. A escolha da situação-problema, neste caso uma história em quadrinhos, tem a ver com o tema em discussão naquele momento do curso: as variedades lingüísticas, a relação fala/escrita, os "erros normais" de escrita que são muitas vezes - e equivocadamente tomados como sinais de patologia.

Nessa história, Chico Bento lê em voz alta para os colegas, a pedido da professora, a bela redação que fez sobre a relação do homem com a natureza. E como ele lê? Lê usando a variedade lingüística que tem. E como ele escreve? Sua escrita traduz a sua fala sendo, portanto, diferente da escrita convencional tal como escreventes que dominam o Português escrito o fazem.

A partir dessa história propomos aos participantes do curso que assumam o lugar da professora de Chico Bento para refletirem sobre a relação normal/patológico no contexto de uso da escrita; a respeito dos interdiscursos (e saberes) que são convocados quando se escreve um texto sobre um determinado tema; sobre o modo como o professor deve intervir nos textos dos alunos para que aprendam a escrever a variedade padrão da língua. 
Prevemos, para esse tipo de atividade, duas rodadas de resposta. A primeira versão da atividade feita pelo participante do curso é lida e comentada pelo formador que observa o entendimento dos conceitos/conteúdos envolvidos. Orientado pelo comentário que recebe do formador - que não tem o objetivo de corrigir supondo uma resposta certa, mas que busca levar o professor a melhor explicitar seu entendimento sobre o conteúdo - o professor em formação escreve uma nova versão da atividade como mostra a Figura 4:
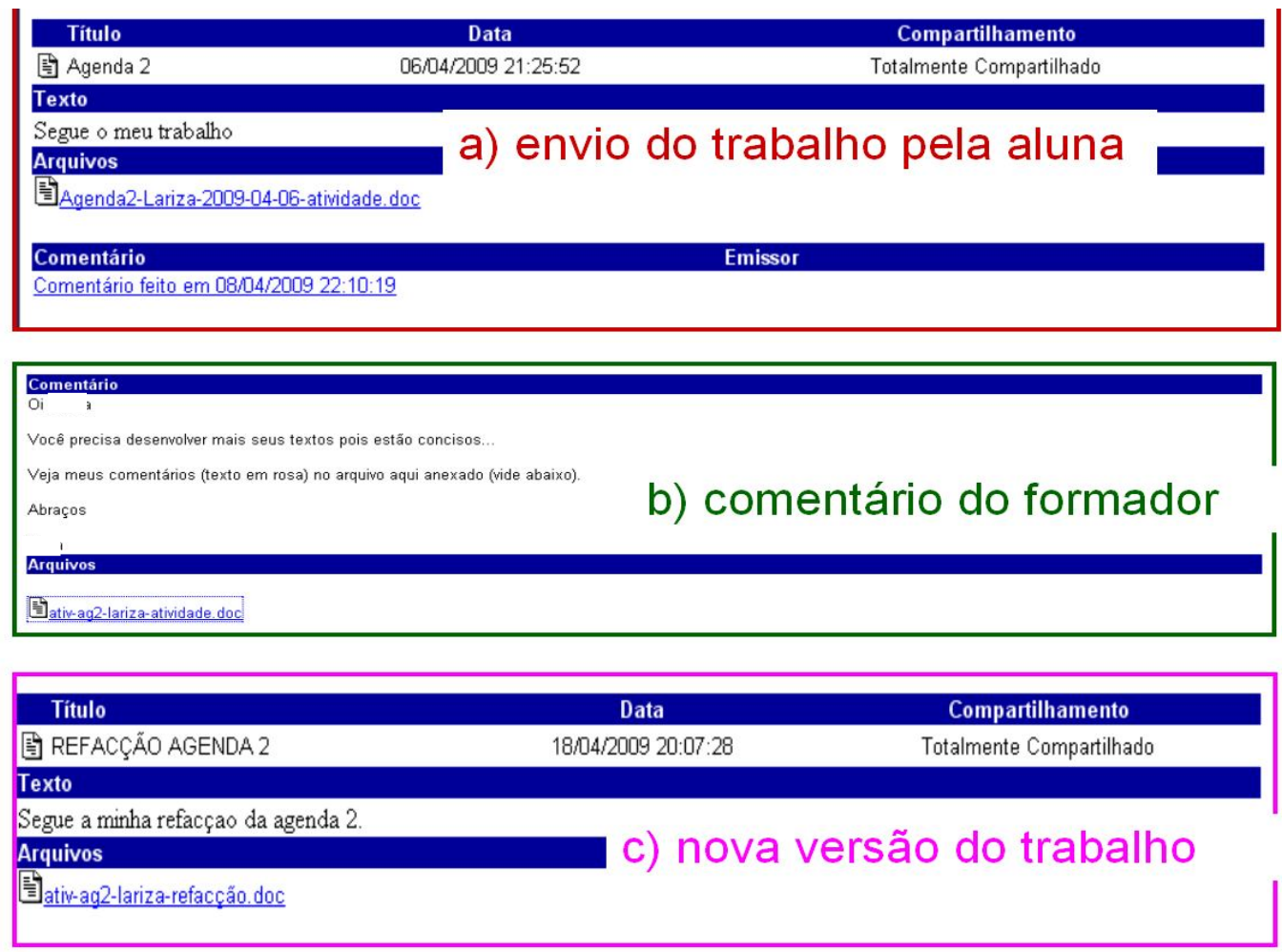

Figura 4: escrita e reescrita da atividade após comentário do formador http://www.cefiel.iel.unicamp.br/ teleduc3/cursos/aplic/index.php?cod_curso=457 10

Cria-se, então, um diálogo "teórico" que promove o entendimento e/ou refinamento dos conteúdos tratados.

\footnotetext{
${ }^{10}$ Exemplo retirado da Agenda 2 da Turma 2 - coordenada pela Profa. Maria Irma Hadler Coudry e por mim - do Curso Linguagem e Letramento nos anos iniciais/educação infantil oferecido para professores do estado do Espírito Santo no período de 13/03/2009 a 23/05/2009.
} 
O terceiro modo de uso do Portfólio é, na verdade, uma variação desse segundo visando um outro objetivo: fazer circular entre os participantes as diferentes soluções que encontram para as questões que propomos. A diferença entre esses modos de usar o Portfólio é que, dessa vez, também os cursistas são convocados a comentar as atividades uns dos outros (Figura 5).

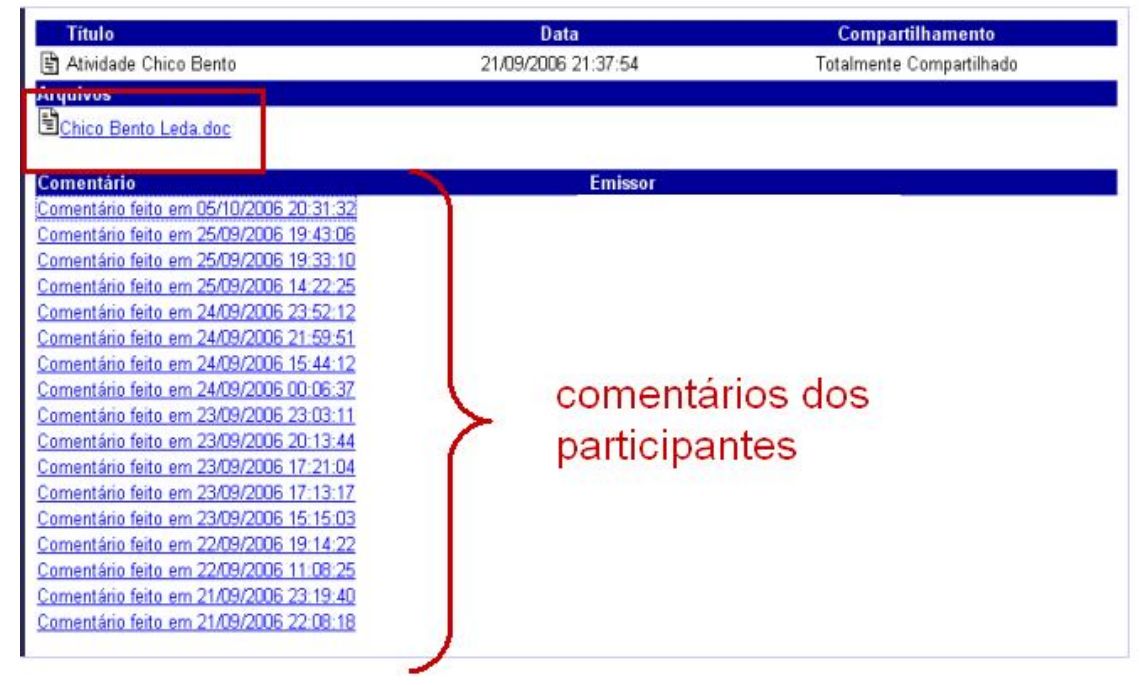

Figura 5: comentários postados pelos participantes na atividade de um dos professores em formação $\underline{\text { http://www.cefiel.iel.unicamp.br/ teleduc3/cursos/aplic/index.php?cod_curso }=340}{ }^{11}$

Essa dinâmica de trabalho permite comparar respostas, analisar diferentes pontos de vista, reinterpretar fatos e conceitos, reescrever a própria resposta levando em conta a leitura que faz do outro.

Cria-se, então, um intenso trabalho coletivo (colaborativo) cujo resultado mediado pelas intervenções dos formadores - é um novo conhecimento, no sentido de ser diferente daquele originalmente pensado/escrito por cada professor em formação e motivado pelo confronto de pontos de vista e de vivências.

\section{COMO O CONHECIMENTO CONSTRÓI NOVAS TECNOLOGIAS?}

As interações que acontecem ao longo do curso - em torno de temas de interesse comum aos que dele participam - concorrem para a emergência de uma comunidade de prática, tal como é definida por Wenger, $2007^{12}$ e, portanto, de diferentes práticas

\footnotetext{
${ }^{11}$ Exemplo retirado do Curso a relação normal/patológico no ensino: cérebro e linguagem oferecido no período de 04/09/2006 a 06/11/2006 coordenado pela Profa. Maria Irma Hadler Coudry e por mim.

12 "Communities of practice are formed by people who engage in a process of collective learning in a shared domain of human endeavour: a tribe learning to survive, a band of artists seeking new forms of expression, a group of engineers working on similar problems, a clique of pupils defining their identity in
} 
discursivas (MAINGUENEAU, 1989; CHARADEAU \& MAINGUENEAU, 2006 ${ }^{13}$ ) por meio das quais os conhecimentos circulam e são produzidos/transformados, sinalizando outras necessidades em termos de ferramentas da linguagem. É dessa forma que novas ferramentas - ao longo da história do TelEduc - são desenvolvidas e incorporadas ao ambiente.

À medida que usamos o ambiente, refinamos a metodologia dos cursos e passamos a querer outras ferramentas e/ou a usar outros recursos das ferramentas já existentes.

O Bate-papo é um bom exemplo. Inspirada nas salas de Bate-papo disponíveis na web foram incorporados outros recursos para que a ferramenta fosse mais bem aproveitada do ponto de vista educacional: pode-se, por exemplo, agendar com antecedência uma sessão e indicar seu assunto; pode-se ainda gravar a sessão para posterior leitura da discussão como pode ser visto na Figura 6:
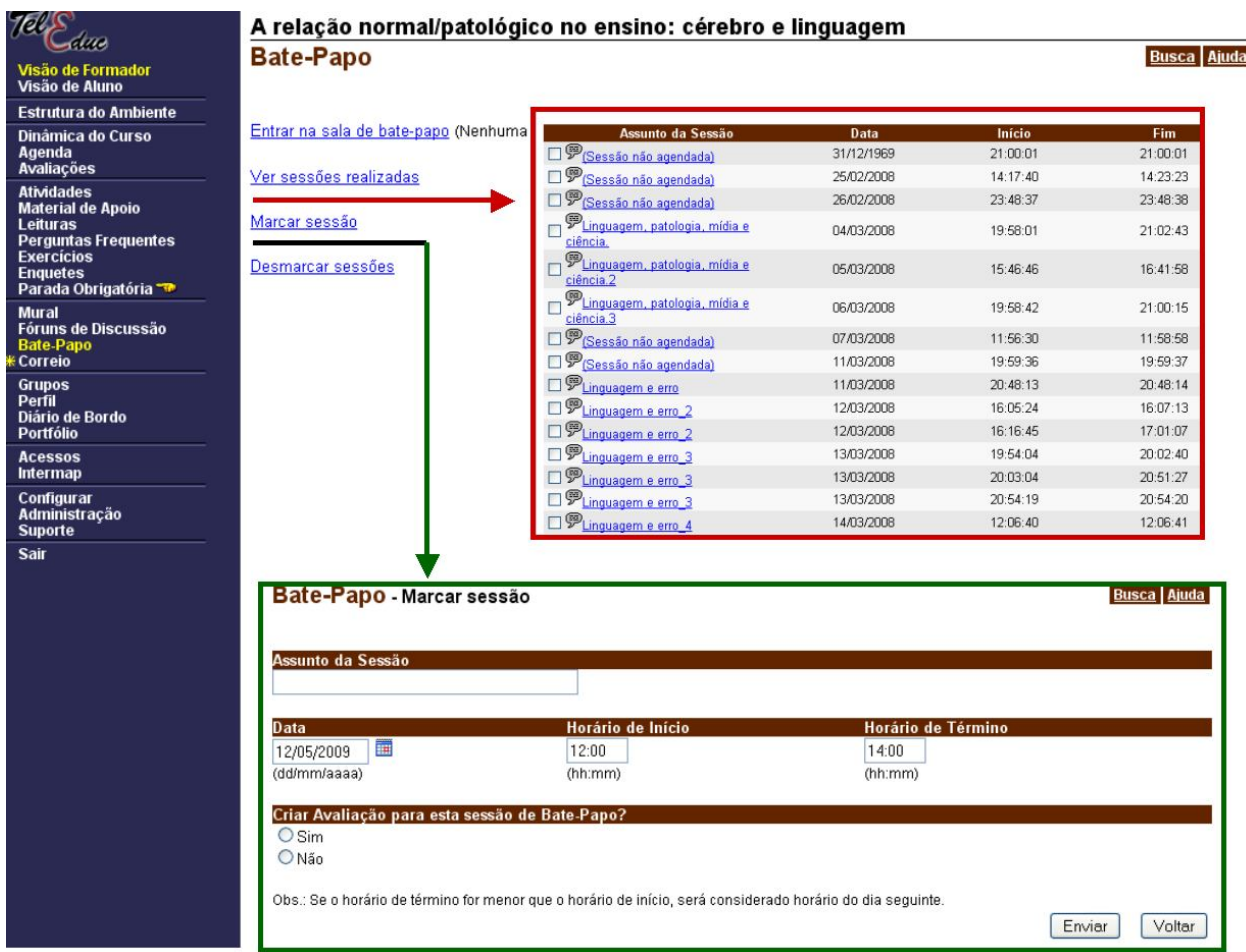

Figura 6: modificações na ferramenta Bate-papo do TelEduc

http://www.cefiel.iel.unicamp.br/ teleduc3/cursos/aplic/index.php?cod_curso=340

the school, a network of surgeons exploring novel techniques, a gathering of first-time managers helping each other cope. In a nutshell: Communities of practice are groups of people who share a concern or a passion for something they do and learn how to do it better as they interact regularly" (WENGER, 2007).

${ }^{13}$ Maingueneau se refere a "prática discursiva" quando se trata de apreender uma formação discursiva como inseparável das comunidades discursivas que a produzem e a difundem. A formação discursiva, então, pode ser pensada ao mesmo tempo como conteúdo, modo de organização dos homens e rede específica de circulação dos enunciados (CHARADEAU \& MAINGUENEAU, 2006: 396). 
Ainda assim, o Bate-papo não deixa de ser um Bate-papo: as mensagens/interlocutores se sobrepõem dando a sensação aos participantes de que estão sempre a "perder o fio da meada", tornando difícil a discussão síncrona de leituras, atividades, reportagens. Além disso, é preciso levar em conta outras dificuldades relacionadas à infra-estrutura usada pelos cursitas (linha discada, computadores mais antigos etc.).

E o que se faz, então? As sessões são agendadas, mas a participação é livre. Funcionam como se fossem "plantões de dúvida": os professores em formação entram na sala e fazem perguntas de diferentes tipos ao formador que está online.

Outras vezes, inspirados no formato do Programa Roda Viva da TV Cultura, propomos uma sessão diferente. Isso aconteceu, por exemplo, quando oferecemos uma Oficina de Trabalho para professores de Instituições de Ensino Superior que são parceiras do CEFIEL. Neste caso, como são poucos participantes e cada um deles atua em uma área específica, imaginamos que essa seria uma maneira diferente de sabermos mais a respeito do trabalho de cada um. Como todos conheciam o programa não foi difícil seguir as regras que regulam as interações que se dão no Roda Viva. Assim, foram estipulados os papéis de entrevistado, moderador e entrevistador. Esse modo de usar o Bate-papo contribui para diminuir o fluxo simultâneo de mensagens e ajuda na organização dos turnos.

Os estudos de Oeiras, no entanto, seguem em outra direção (OEIRAS, 2005; OEIRAS et al., 2005). A autora apresenta o Bate-papo coordenado ${ }^{14}$, cujo desenvolvimento se baseia na análise do modo como a linguagem funciona em certas práticas sociais (certos gêneros discursivos - cf. BAKHTIN, 1997) - assembléia, entrevista, seminário, conversa informal - e propõe um redesign da interface do Batepapo "convencional" de modo a explicitar as regras de conduta que orientam tais práticas, como mostra a Figura 7:

\footnotetext{
${ }^{14}$ Em uma sessão coordenada existem 3 papéis: coordenador, VIPs e platéia. O papel de coordenador é atribuído a uma única pessoa que fará o gerenciamento da sessão. Os VIPs são pessoas com privilégios especiais e a platéia é formada pelos demais participantes. No momento do agendamento de uma sessão é obrigatória a especificação do coordenador e das pessoas que farão parte da platéia (OEIRAS et al., 2005).
} 


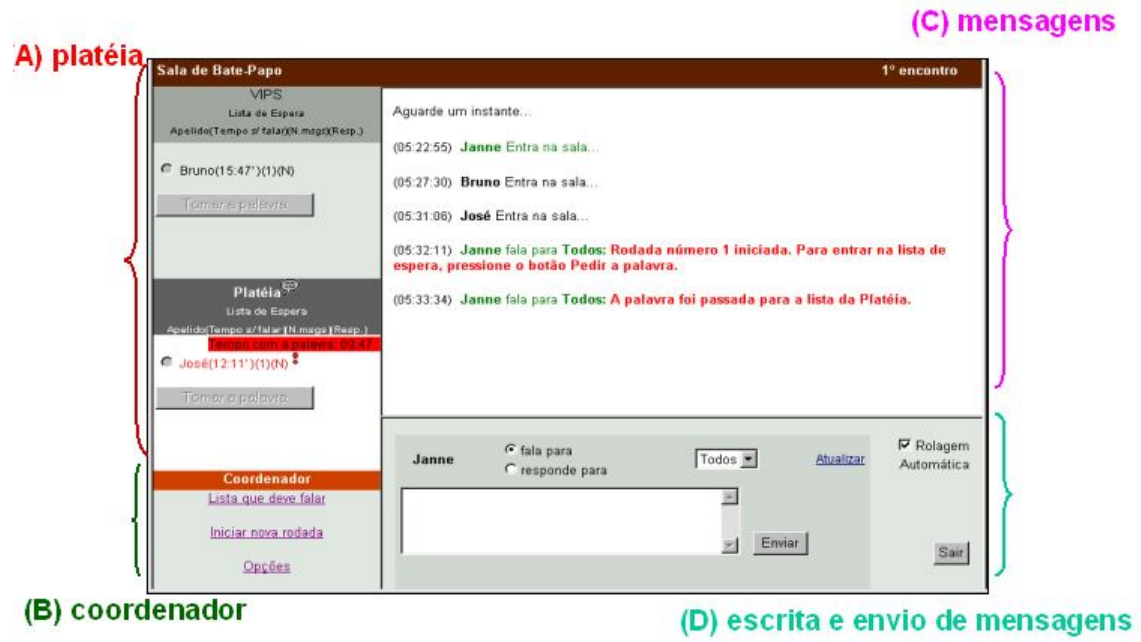

Figura 7: visão geral do coordenador do Bate-papo coordenado

No caso do Plantão de Dúvida e do Roda Viva ajustamos nossas práticas sociais ao Bate-papo tal como ele foi desenvolvido, adotando certas regras que balizam outras práticas que se dão na escola ou em um programa de TV; no caso do Bate-papo coordenado é a ferramenta da linguagem que se ajusta a diferentes práticas sociais mediadas pela linguagem.

A manutenção do nome - Bate-papo - na ferramenta do ambiente aliado ao fato de alguns professores já conhecerem essa ferramenta na web os faz supor que na sala sempre "tem alguém", o que não é necessariamente verdadeiro, já que os horários das sessões são previamente divulgados.

Os nomes das ferramentas e de seus recursos são referências importantes para a compreensão de suas funções: certos nomes sugerem ao usuário um gênero discursivo o que, em alguma medida, tem um efeito sobre o que se escreve e o modo como se escreve, especialmente se se trata de um usuário pouco familiarizado com espaços de leitura/escrita virtuais (ROCHA et al., 2001; FREIRE, 2003; FREIRE et al., 2007). Outros nomes remetem os usuários a certas funções específicas. Não foi sem surpresa, à época em que o Brasil estava enfrentando problemas relacionados à energia elétrica (os famosos apagões), que vimos um professor usuário do TelEduc usar a ferramenta Parada Obrigatória para avisar aos alunos que o servidor ficaria fora do ar. A ferramenta, no entanto, foi desenhada com o objetivo de disponibilizar materiais que possam ajudar os cursistas a refletir sobre tópicos importantes relacionados ao curso em questão. 


\section{COMO AS NOVAS TECNOLOGIAS DÃO CORPO AO CONHECIMENTO?}

Para responder a essa questão vou me ater ao modo como usuários novatos vão gradativamente adquirindo - e compreendendo - novas palavras/expressões que permitem a eles, de fato, interagir com o ambiente.

Veja-se o depoimento no Diário de Bordo de uma aluna do Instituto de Estudos da Linguagem (IEL/Unicamp) que participou de um curso semipresencial de formação de monitores do CEFIEL, ocasião em que vivenciam situações no papel de aluno e de formador $^{15}$ :

"Desde o dia em que iniciei o curso até agora me deparei com as sensações
mais estranhas. No encontro presencial, a primeira sensação foi a de me
maravilhar com tudo o que via e ouvia. Depois fiquei meio desesperada
porque eu tinha que fazer um montão de coisas e o que eu tinha na cabeça
não se materializava, eu não sabia que botão apertar ou em que lugar entrar
no computador. Depois percebi que não adianta falar que você precisa de
tantas horas para fazer as atividades durante a semana. E por quê? Porque,
por exemplo, tem passos que eu sigo no computador e não dá certo."

A leitura que um usuário novato - pouco familiarizado com a tecnologia, como ocorre com a maior parte dos professores em formação dos cursos do CEFIEL - faz da interface do TelEduc (o que inclui o nome das ferramentas) pode ser vista como uma aproximação gradual ${ }^{16}$ de suas funções e recursos. O usuário decifra - em busca de pistas e relações de sentido - a interface do programa, representada por suas telas com cores, botões, links e nomes, conforme mostra a Figura 8:

\footnotetext{
${ }^{15}$ Trata-se do III Curso de Formação de Monitores do CEFIEL oferecido no período de 09/03/2009 a 24/04/2009, sob minha coordenação.

${ }^{16}$ Dascal, em um de seus textos, diz que "a compreensão de uma enunciação ou de um texto" - ao que eu acrescentaria, de um programa computacional, de um site etc. - "envolve sempre uma pluralidade de habilidades, níveis e sistemas diferentes de conhecimento, tanto lingüístico quanto não lingüístico. (...) Em vista dessa multiplicidade inerente ao processo de compreensão, é preciso encará-lo como sendo não tanto uma questão de sim/não, de tudo/nada, e mais como um processo de aproximação gradual." (DASCAL, s/d: 1).
} 


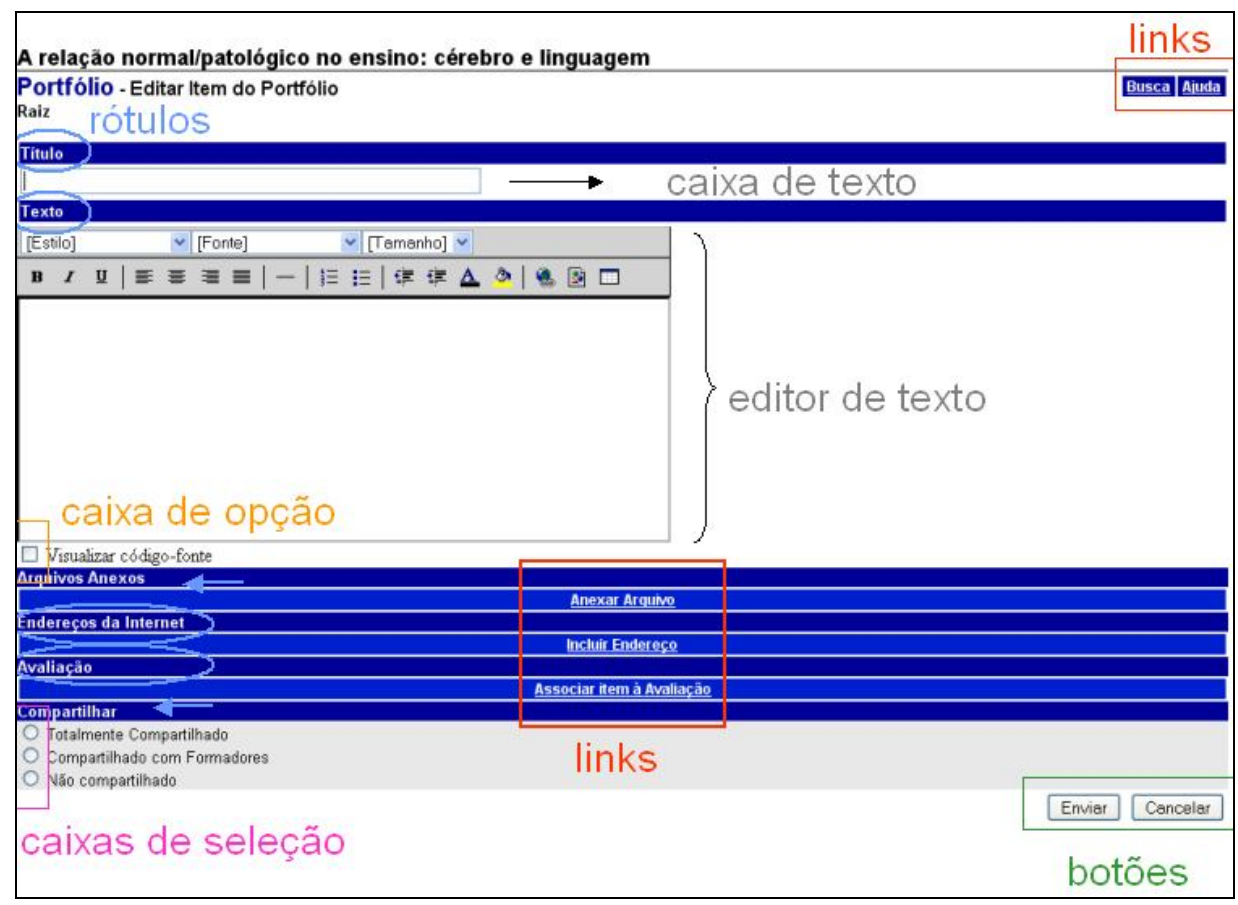

Figura 8: visão geral da tela de inserção de arquivos do Portfólio

Existem termos técnicos cujo entendimento não é trivial (Figura 9).

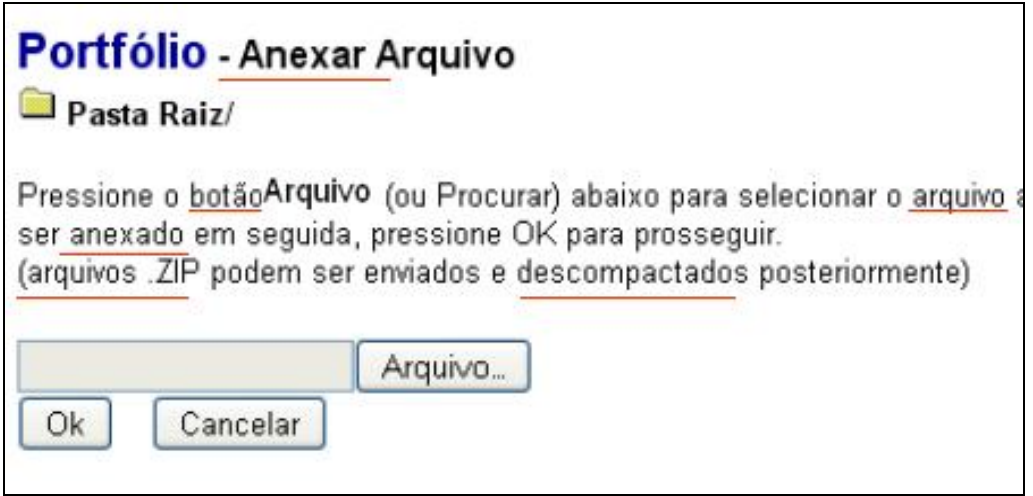

Figura 9: janela de anexar arquivos no Portfólio

Aos olhos de um usuário experiente pode parecer simples, mas esse processo pressupõe um conjunto complexo de operações lingüísticas e cognitivas.

Veja-se o que diz no Diário de Bordo uma participante veterana do Curso de monitores do CEFIEL, "ex-avessa" à tecnologia e que o faz pela segunda vez:

"Relembrando o apuro do curso passado, nem acreditei, pois agora as palavras têm significado e é como se houvesse tradução. Fica difícil hoje, procurar entender o que eu não entendia nas palavras 'incluir um 
arquivo ou anexar.' É como quando a criança aprende a ler, se apossando do código, decifrando-o dentro de um contexto que lhe é favorável e descobre o seu significado. Não dá mais para não ler.....Provavelmente será mais leve este meu percurso no TelEduc..."

Quero com isso dizer que para fazer parte dessa comunidade particular - a dos participantes de um curso semipresencial - de alguma forma é preciso não só aprender a usar as ferramentas, como também aprender a falar sobre elas, adquirir um conjunto de expressões que se referem àquele domínio de interpretação particular. Isso não é simples. Muitas vezes o usuário novato não sabe, nem ao menos, descrever o que está acontecendo para que alguém possa lhe ajudar.

Veja-se a mensagem que recebi, por e-mail externo ao ambiente, de uma cursista:

não estou conseguindo acessar o link teleduk

O que responder? Escrevo:

Oi,

Você está fazendo nosso curso?

Pode, por favor, enviar o link que está tentando abrir para podermos ajudá-la (sabe copiar da mensagem que recebeu e colar aqui?)

O link não abre ou o seu login/senha não funcionam?

Precisamos de mais informações para poder ajudá-la.

Aguardamos,

Como explicar a ela o que pode estar acontecendo se ela não entender o que quero dizer com link, copiar/colar, login/senha? É como se ela fosse uma estrangeira em um país em que se fala uma língua que não lhe diz nada.

As funções das ferramentas do ambiente cujos nomes não têm correlatos na web são ainda mais abertas em termos de interpretação, muito embora, seus nomes sugiram certos usos. Esse é o caso do Diário de Bordo, do Mural, da Parada Obrigatória, do 
Material de Apoio. Veja-se na Figura 10 uma mesma mensagem de um mesmo participante, postada no Mural e no Fórum:

\begin{tabular}{lc|}
\hline (SP)_T5_Linguagem e Letramento nos anos iniciais/ed \\
\hline Mural - Ver Mensagem & Busca Aiuda \\
\multicolumn{1}{|c|}{ Emissor } & Data \\
Titulo & $02 / 05 / 2009$ \\
$23: 10: 26$ & \\
Dúvida!!!! & \\
Anotaçäo & \\
Olá, & \\
Onde posso postar meu comentário sobre o primeiro encontro presencial? No \\
diário de bordo ou em algum outro espaço....? \\
Aguardo um retorno! \\
Abraços
\end{tabular}

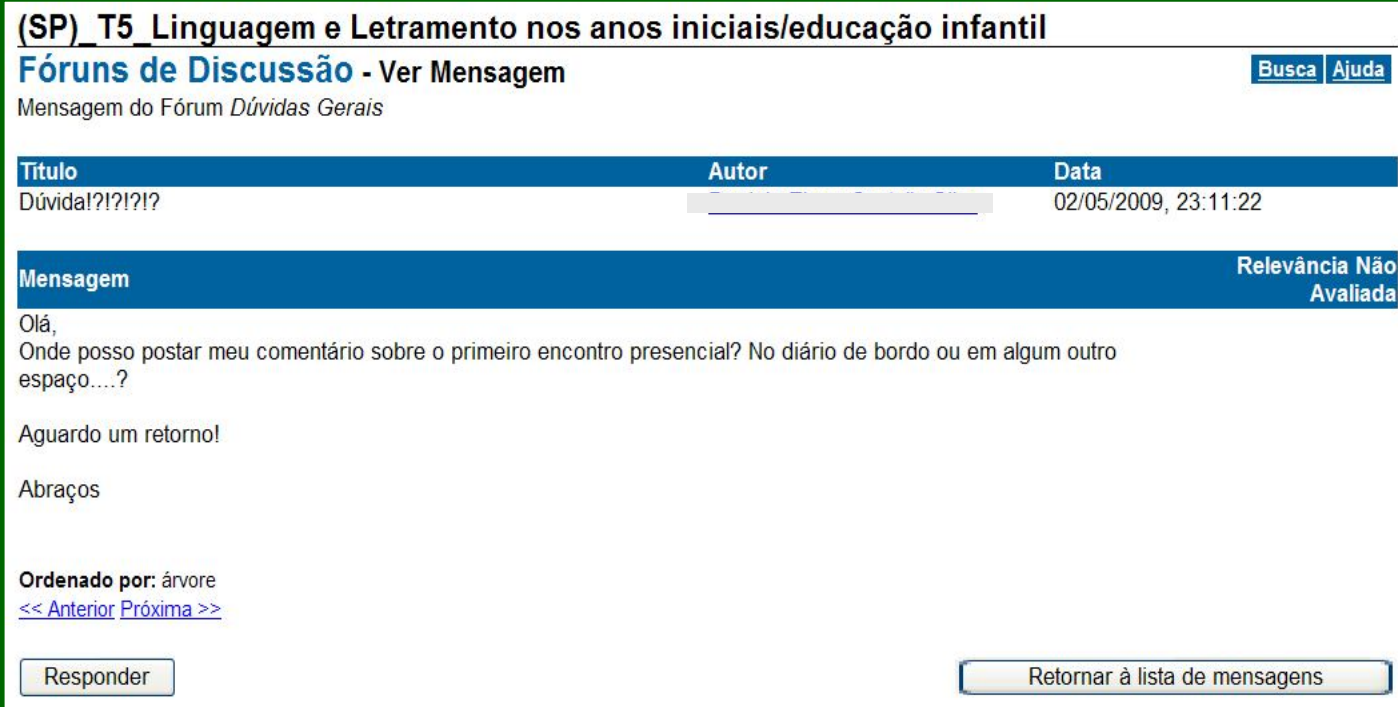

Figura 10: Mesma mensagem no Mural e no Fórum http://www.cefiel.iel.unicamp.br/ teleduc3/cursos/aplic/index.php?cod_curso $=477{ }^{17}$

Embora cada ferramenta tenha um rótulo próprio e sua função original - aquela pensada pelos desenvolvedores do ambiente - seja apresentada na ferramenta Estrutura do Ambiente, como uma espécie de glossário, não é óbvio o que se escreve onde. $\mathrm{O}$ exercício da linguagem vai além das ferramentas e para se saber onde se escreve o que é

\footnotetext{
${ }^{17}$ Exemplo retirado da Turma 5 - coordenada pela Profa. Maria Irma Hadler Coudry e por mim - do Curso Linguagem e Letramento nos anos iniciais/educação infantil oferecido para professores do estado de São Paulo no período de 24/04/2009 a 27/06/2009.
} 
preciso conhecê-las. Na dúvida, escreve-se em todos os possíveis lugares, como é o caso dessa professora em formação.

Trata-se de um aprendizado que se dá online, isto é, à medida que se interage com (o ambiente) e por meio do ambiente com o outro. Assim, o usuário legitima aquela interface (com todos os seus elementos) como uma espécie de "língua" que lhe permite interagir com o computador. Uma "língua" com recursos expressivos, emprestados da sua língua, com funções específicas.

É o que a aluna do IEL - autora do primeiro Diário de Bordo que apresentei parece estar em vias de fazer:

Sabem o que reparei em mim mesma? Não estou mais tão desesperada. Acho que estou começando a me sentir confiante diante desse negócio de link, de agenda, de portfólio etc... Ainda tem algumas coisas que me apavoram, mas esta semana vou aprender, por exemplo: zipar, fazer um arquivo de vídeo. Um abração a todas. Obrigada pela ajuda.

Ela percebeu, por exemplo, para que serve o Diário de Bordo.

\section{CONSIDERAÇÕES FINAIS}

Ao finalizar esse texto - relendo o que escrevi - me dei conta que o próprio ambiente de ensino-aprendizagem ilustra as questões que nortearam minha reflexão com o objetivo de discutir a relação linguagem e conhecimento a partir do papel da tecnologia em nossa sociedade.

O TelEduc pode ser visto como o produto de um conjunto de conhecimentos estreitamente relacionados ao exercício social da linguagem em meio a diferentes práticas sociais de escrita, em especial.

Suas primeiras versões pautavam-se em nossas experiências em cursos de formação de professores na área de Informática na Educação: tentávamos reproduzir em alguma medida - nossas metodologias presenciais bem-sucedidas para o ambiente virtual. Essa, então, "nova tecnologia", sem dúvida, interferiu de maneira definitiva 
no(s) modo(s) de se construir conhecimento. Cursos como os do CEFIEL são uma prova disso.

O uso continuado do ambiente - com diferentes usuários e em diferentes contextos de ensino-aprendizagem - impulsionaram mudanças, colocando desafios que ainda não haviam sido pensados.

Nesse sentido, a cada nova versão, ela mesma, é um "novo conhecimento" que apresenta novas tecnologias.

A interface do ambiente - sua nomenclatura com cores, botões, caixas, links, rótulos - dão corpo a um conhecimento - cursos à distância, semipresenciais metodologias diferenciadas, hoje cada vez menos orientadas por metodologias presenciais, apontando para a construção de uma cultura própria.

Para terminar gostaria de mostrar - ainda que esse texto tenha focado nas interações que se dão no ambiente virtual - que o conhecimento que ali é repetido, construído, transformado, extravasa e ganha sentido onde queremos mesmo que ele ganhe: na vida dos professores, na sua relação com os alunos, na sala de aula, na escola. Observem duas mensagens do Fórum de discussão de duas professoras de uma mesma escola a respeito dos conteúdos do curso ${ }^{18}$ :

\section{Professora_1}

Fulana, é legal como este curso mesmo a distancia está nos aproximando, ultimamente no recreio da escola, o nosso comentário é sobre as atividades, as leituras, as considerações das tutoras. Nossa discussão não consiste mais em "atacar" determinado aluno, de que ele não aprende, ou está na escola só para atrapalhar, mas sim de debater a melhor maneira de ajudá-lo. Foi isso que aconteceu ontem, a respeito da atividade dessa semana, uma professora relatou e todas concordamos, que dizemos que o aluno é disléxico sem ao menos entendermos o significado do termo dislexia, como se fosse uma moda. Ou apenas como professoras para livrar-nos da preocupação de termos de buscar maneiras diferentes deste aluno aprender.

18 Exemplos gentilmente cedidos pela Profa. Tânia Alkmim, coordenadora da Turma 3 do Curso Linguagem e Letramento nos anos iniciais/educação infantil oferecido para professores do estado do Espírito Santo no período de 13/03/2009 a 23/05/2009. 


\section{Professora_2:}

Nós passamos quase o intervalo todo discutindo e dando opiniões sobre o conteúdo das atividades. Mesmo aquelas que não fazem parte do curso acabam entrando na conversa e participando das nossas idéias! Acho que nos tornamos, por tabela, multiplicadoras do curso! Não é bom?!

\section{REFERÊNCIAS BIBLIOGRÁFICAS}

BRAGA,D.B.; ICARTE,I. Letramento e tecnologia. Campinas: CEFIEL/IEL/Unicamp, 2005, 53 p.

BAKHTIN, M. Os gêneros do discurso. In: BAKHTIN, M. Estética da Criação Verbal. São Paulo: Martins Fontes. 1997, p. 277-326.

CHARAUDEAU, P.; MAINGUENEAU, D. Dicionário de análise do discurso. São Paulo: Contexto. 2006, 555p.

CORRÊA, M. L. G. Letramento e heterogeneidade da escrita no ensino de português. In: SIGNORINI, Inês (org.). Investigando a relação oral/escrito e as teorias do letramento. Campinas: Mercado de Letras. 2001, p. 135-166.

DASCAL, M. Dez maneiras de ser incompreendido (e algumas sugestões para evitálas).(mimeo.). s/d, $19 \mathrm{p}$.

FREIRE, F. M. P. Armadilhas virtuais na educação de leitores. In: Anais do $16^{o}$ Congresso de Leitura do Brasil. Campinas-SP, 2007.

Disponível em: www.alb.com.br/anais16/conferencias/03fernandafreire.pdf Acessado em 24 de julho de 2009.

. Formas de Materialidade Lingüística, Gêneros de Discurso e Interfaces. In: SILVA, E. T. (Coord.); FREIRE, F. M. P.; ALMEIDA, R. Q.; AMARAL, S. A leitura nos oceanos da Internet. São Paulo: Cortez, 2003 p. 65-88.

FREIRE, F., CAVALCANTI, M.; POSSENTI, S.; KLEIMAN, A. Leitura e escrita via Internet: formação de professores nas áreas de alfabetização e linguagem. In: Trabalhos em Lingüística Aplicada. 2007, v.46(1), p.93-111. 
MAINGUENEAU, D. Termos-chave da Análise do Discurso. Belo Horizonte: Editora da UFMG, 1998.

. Novas Tendências em Análise do Discurso. Campinas: Pontes, 1989,198p.

MARCUSCHI, L. A. Gêneros textuais emergentes no contexto da tecnologia digital. In: .; XAVIER, A. C. (orgs.). Hipertexto e gêneros digitais. Rio de Janeiro: Lucerna. 2004, p. 13-67.

. A questão do suporte dos gêneros textuais. In: DLCV: Língua, lingüística e literatura. João Pessoa, 2003, v. I, n. 1, p. 9-40.

OEIRAS, J. Y. Y. Design de ferramentas de comunicação para colaboração em ambientes de educação a distância. Campinas: IC/Unicamp, 2005. Doutorado.

. ; FREIRE, F. M. P.; LACHI, R. L.; ROCHA, H. V. Desenvolvimento de uma ferramenta de bate-papo com mecanismos de coordenação baseados na linguagem em ação. Porto Alegre-RS: Revista Novas Tecnologias na Educação. 2005, v. 3, n. 2. PAIVA, V. L. M. de O. (2004) Email: um novo gênero textual. In: MARCUSCHI, L. A.; XAVIER, A. C. (orgs.). Hipertexto e gêneros digitais. Rio de Janeiro: Lucerna. 2004, p. 68-90.

ROCHA, H. V.; FREIRE, F. M. P.; OEIRAS, J. Y. Y.; ROMANI, L. A. S. Design de Ambientes de Ead: (re)significações do usuário. Florianópolis, SC: IV Workshop sobre Fatores Humanos em Sistemas Computacionais. 2001, p. 84-95.

TAKAHASHI, Tadao (org.). Sociedade da informação no Brasil: livro verde. Brasília: Ministério da Ciência e Tecnologia, 2000.

WENGER, E. Communities of Practice: a Brief Introduction. In: www.ewenger.com/theory/. 2007. Acessado em 24 de julho de 2009. 


\section{Para citar essa obra:}

FREIRE, Fernanda. Linguagem, tecnologia, conhecimento e suas relações no contexto de formação continuada de professores. RUA [online]. 2009, no. 15. Volume 2 - ISSN 1413-2109

Consultada no Portal Labeurb - Revista do Laboratório de Estudos Urbanos do Núcleo de Desenvolvimento da Criatividade

http://www.labeurb.unicamp.br/rua/

Laboratório de Estudos Urbanos - LABEURB

Núcleo de Desenvolvimento da Criatividade - NUDECRI

Universidade Estadual de Campinas - UNICAMP

http://www.labeurb.unicamp.br/

Endereço:

Rua Caio Graco Prado, 70

Cidade Universitária “Zeferino Vaz" - Barão Geraldo

13083-892 - Campinas-SP - Brasil

Telefone/Fax: (+55 19) 3521-7900

Contato: http://www.labeurb.unicamp.br/contato 